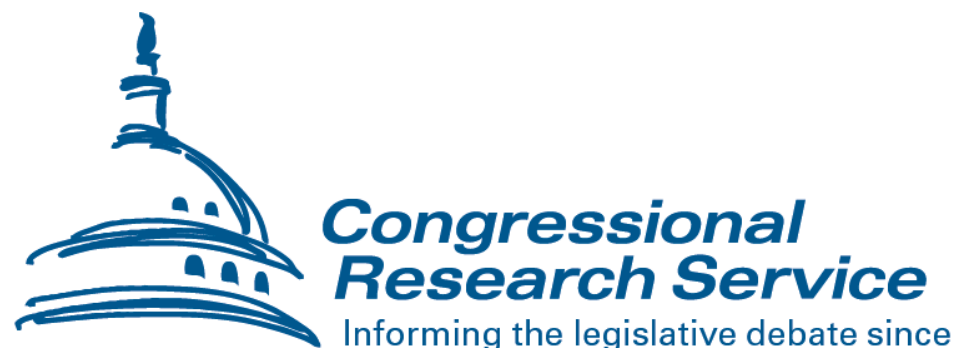

Informing the legislative debate since 1914

\title{
Supplemental Security Income (SSI)
}

\author{
William R. Morton \\ Analyst in Income Security
}

January 23, 2014

The House Ways and Means Committee is making available this version of this Congressional Research Service (CRS) report, with the cover date shown, for inclusion in its 2014 Green Book website. CRS works exclusively for the United States Congress, providing policy and legal analysis to Committees and Members of both the House and Senate, regardless of party affiliation. 


\section{Summary}

The Supplemental Security Income (SSI) program, enacted in 1974, is a needs-based program that provides cash benefits designed to ensure a minimum income to aged, blind, or disabled persons with limited income and assets. The SSI program is a means-tested program that does not have work or contribution requirements, but restricts benefits to those who meet asset and resource limitations. In December 2013, the SSI program had more than 8.3 million participants, who received over $\$ 4.6$ billion in benefits. The costs for benefit payments and administrative expenses for the SSI program were over $\$ 53$ billion in FY2013. Funding for the SSI program is provided by Congress in the annual Departments of Labor, Health and Human Services, Education and Related Agencies appropriations bill.

For adults, disability is defined as the inability to engage in substantial gainful activity (SGA) by reason of a medically determinable physical or mental impairment expected to result in death or last at least 12 months. In general, the worker must be unable to do any kind of work that exists in the national economy, taking into account age, education, and work experience. A child under age 18 may qualify as disabled if he or she has an impairment that results in "marked and severe" functional limitations. For adults aged 65 or older, it is possible to qualify for SSI benefits without being disabled. Most adult SSI recipients have other income; their countable income is subtracted from the federal benefit rate to determine their SSI eligibility and payment amount.

The maximum federal SSI payment, referred to as the federal benefit rate, is $\$ 721$ per month for an individual living independently and $\$ 1,082$ for a couple living independently in 2014. Federal SSI benefits are adjusted annually to reflect changes in the cost of living. A $1.5 \%$ cost-of-living adjustment (COLA) was applied for 2014, following a 1.7\% COLA in 2013. In December 2013, the average monthly federal SSI payment was $\$ 630.98$ for children under the age of $18, \$ 546.38$ for adults aged 18 to 64 , and $\$ 425.09$ for adults aged 65 or older. All but six states and the Commonwealth of the Northern Mariana Islands supplement the federal SSI benefit with additional payments, which are partially or wholly administered by the federal government, or by the states themselves. SSI recipients are also automatically eligible for the Supplemental Nutrition Assistance Program (SNAP) and are generally eligible for Medicaid. 


\section{Contents}

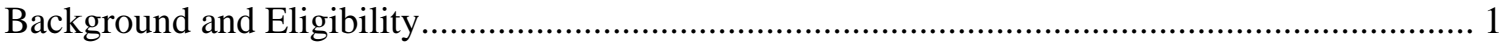

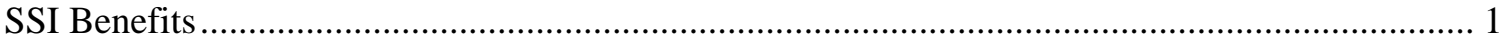

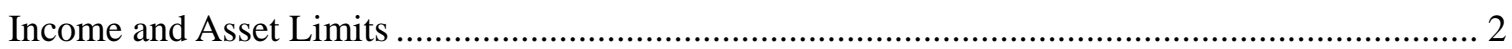

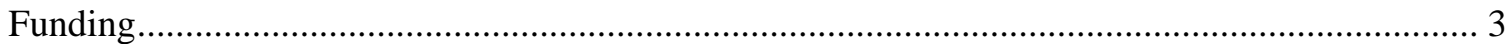

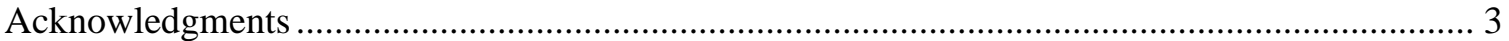




\section{Background and Eligibility}

The Supplemental Security Income (SSI) program, Title XVI of the Social Security Act, was enacted in 1972 and implemented in 1974 to assure a minimum cash income to all aged, blind, or disabled persons. ${ }^{1}$ SSI is provided to eligible aged or disabled individuals or couples who have limited income and resources. For adults, disability is defined as the inability to engage in substantial gainful activity (SGA) by reason of a medically determinable physical or mental impairment expected to result in death or last at least 12 months. In general, the worker must be unable to do any kind of work that exists in the national economy, taking into account age, education, and work experience. A child under the age of 18 may qualify as disabled if he or she has an impairment that results in "marked and severe" functional limitations. ${ }^{2}$ Adults aged 65 or older may qualify for SSI benefits without being disabled.

SSI is administered by the Social Security Administration (SSA) and operates in the 50 states, the District of Columbia, and the Commonwealth of the Northern Mariana Islands. ${ }^{3}$ To qualify for SSI, a person must be a citizen of the United States or a "qualified alien" and either a resident of the United States or the Northern Mariana Islands, a child of a person in the military stationed outside the United States, or a student temporarily abroad. ${ }^{4}$ Other requirements related to residence in certain public institutions, absence from the United States, filing for other potential benefits, and fugitive felon and probation/parole violator status also apply. ${ }^{5}$ In December 2013, the SSI program had more than 8.3 million recipients, who received over $\$ 4.6$ billion in benefit payments. ${ }^{6}$ Of these recipients, more than 1.3 million were children under the age of 18 , almost 5.0 million were adults between the ages of 18 and 64, and just over 2.1 million were adults aged 65 or older. $^{7}$

\section{SSI Benefits}

The maximum federal SSI payment, referred to as the federal benefit rate, is $\$ 721$ per month for an individual living independently and \$1,082 for a couple living independently in 2014. All but six states and the Commonwealth of the Northern Mariana Islands supplement the federal SSI benefit with additional payments. Fourteen states and the District of Columbia have state supplements that are either partially or wholly administered by the SSA, and 34 states self-

\footnotetext{
${ }^{1}$ Social Security Amendments of 1972 (P.L. 92-603).

${ }^{2}$ For additional information on the definition of disability used to determine eligibility for the SSI program, see CRS Report RL32279, Primer on Disability Benefits: Social Security Disability Insurance (SSDI) and Supplemental Security Income (SSI), by Umar Moulta-Ali.

${ }^{3}$ In the remaining U.S. territories there is no SSI program. However, in all U.S. territories except American Samoa and the Commonwealth of the Northern Mariana Islands, there is a territorial program for aged, blind, and disabled people primarily funded by the Department of Health and Human Services.

${ }^{4}$ See CRS Report RL33809, Noncitizen Eligibility for Federal Public Assistance: Policy Overview and Trends, by Ruth Ellen Wasem.

${ }^{5}$ See CRS Report RL33394, Social Security Administration: Suspension of Benefits for Fugitive Felons and the Agency's Response to the Fowlkes Decision, by Scott D. Szymendera and Kathleen S. Swendiman.

${ }^{6}$ Social Security Administration, SSI Monthly Statistics, December 2013, Table 1 available at http://www.ssa.gov/ policy/docs/statcomps/ssi_monthly/2013-12/table01.html.

${ }^{7}$ Ibid., Table 2.
}

Congressional Research Service 
administer their supplements. ${ }^{8}$ Federal SSI benefit maximums are adjusted annually using the Consumer Price Index for Urban Wage Earners and Clerical Workers (CPI-W) to reflect changes in the cost of living. After a $1.7 \%$ increase in 2013, a $1.5 \%$ COLA was applied for $2014 .{ }^{9}$

Most SSI recipients have other income; their countable income is subtracted from the federal benefit rate to determine their SSI eligibility and payment amount. In calculating countable income, SSI provides for certain income exclusions (e.g., the first $\$ 20$ of monthly unearned income; the first $\$ 65$ plus one-half of remaining monthly earned income). In December 2013, the average monthly federally administered SSI payment was $\$ 630.98$ for children under the age of $18, \$ 546.38$ for adults aged 18 to 64 , and $\$ 425.09$ for adults aged 65 or older. ${ }^{10}$

SSA generally sends the monthly SSI payments directly to the recipient. However, SSA assigns representative payees to (1) minors, (2) individuals incapable of physically or mentally managing their own benefits, and (3) individuals declared legally incompetent by a court.

SSI recipients living alone or in households in which all members receive SSI benefits are also automatically eligible for the Supplemental Nutrition Assistance Program (SNAP). ${ }^{11}$ In most cases an SSI recipient is eligible for Medicaid. ${ }^{12}$

\section{Income and Asset Limits}

The SSI program generally counts all types of income in determining eligibility and payment amounts. ${ }^{13}$ In some cases, the income and resources of non-recipients are counted in determining SSI eligibility and benefit amounts. This process is called "deeming" and is applied in cases in which an eligible child lives with an ineligible parent, an eligible individual lives with an ineligible spouse, or an eligible non-citizen has a sponsor. ${ }^{14}$ In general, an SSI recipient can have assets, with the exception of a home, car, and household items, worth no more than $\$ 2,000$ and beneficiary-couples can have countable assets worth no more than $\$ 3,000$.

\footnotetext{
${ }^{8}$ Arizona, Mississippi, North Dakota, West Virginia, and the Northern Mariana Islands do not pay a supplement to people who receive SSI. See "Understanding Supplemental Security Income," available on the SSA website at http://www.socialsecurity.gov/ssi/text-benefits-ussi.htm.

${ }^{9}$ For additional information on the cost-of-living adjustments to SSI benefits see CRS Report 94-803, Social Security: Cost-of-Living Adjustments, by Gary Sidor. For additional information on the CPI-W, see CRS Report RL30074, The Consumer Price Index: A Brief Overview, by Brian W. Cashell.

${ }^{10}$ Social Security Administration, SSI Monthly Statistics, December 2013, Table 7, available at http://www.ssa.gov/ policy/docs/statcomps/ssi_monthly/2013-12/table07.html.

${ }^{11}$ SNAP is the former food stamp program. In California, SSI recipients cannot receive SNAP; instead, the state adds additional money for food purchases to the SSI payment. For additional information, see CRS Report R42505, Supplemental Nutrition Assistance Program (SNAP): A Primer on Eligibility and Benefits, by Randy Alison Aussenberg.

${ }^{12}$ See CRS Report RL33340, Cash and Noncash Benefits for Persons with Limited Income: Eligibility Rules, Recipient and Expenditure Data, FY2002-FY2004, coordinated by Karen Spar.

${ }^{13}$ See CRS Report RS20294, Supplemental Security Income (SSI): Income/Resource Limits and Accounts Exempt from Benefit Determinations, by Umar Moulta-Ali.

${ }^{14}$ See CRS Report RL33675, Potential Effect of Marriage on Supplemental Security Income (SSI) Eligibility and Benefits, by Scott D. Szymendera.
} 


\section{Funding}

Federal SSI benefits and administrative costs are paid from federal general revenues and state supplements are paid from state funds. For FY2013, the net cost of the SSI program (including administrative expenses and benefit payments) was 53.2 billion. ${ }^{15}$ Funding for the SSI program is provided by Congress in the annual Departments of Labor, Health and Human Services, Education and Related Agencies appropriations bill.

\section{Acknowledgments}

This report was originally written by Scott Szymendera with research assistance provided by Robert Valenti. Umar Moulta-Ali contributed to earlier versions of this report. All questions should be addressed to the current author.

${ }^{15}$ Social Security Administration, Agency Financial Report for Fiscal Year 2013, p. 77, http://www.socialsecurity.gov/ finance. 